\title{
Spectrum and contributing factors of renal diseases among Jordanian children
}

\author{
Sumia Abded Alhafeth Alkadomi ${ }^{1}$, Najah Sami Shawish ${ }^{* 1,2}$, Saiel Hayat Saleh ${ }^{3}$, Amani Mustafa Alqudah ${ }^{1}$ \\ ${ }^{1}$ Pediatric Department, Jordanian Ministry of Health, Jordan \\ ${ }^{2}$ Department Of Nursing, Faculty Of Nursing, Al-Balqa' Applied University, Jordan \\ ${ }^{3}$ Faculty of Medicine, Hashemite University, Jordan
}

Received: September 13, 2019

DOI: $10.5430 / \mathrm{cns} . v 7 \mathrm{n} 4 \mathrm{p} 70$
Accepted: November 24, 2019 Online Published: November 29, 2019

URL: https://doi.org/10.5430/cns.v7n4p70

\begin{abstract}
Renal diseases are a significant cause of morbidity and mortality in children. They can affect children in various ways: they vary from completely treatable without long-lasting consequences to severe disorders such as chronic kidney disease. The causes of renal disease may differ from one country to another. Understanding the spectrum and identifying the contributing factors of renal diseases in a specific country promote early diagnosis, facilitate treatment, and prevent complications such as renal failure and end-stage kidney disease. This study was conducted to establish the spectrum and contributing factors to renal diseases among Jordanian children receiving health care in a tertiary hospital in Amman, Jordan (Prince Hamza Hospital). A convenience sample of 129 children diagnosed with renal diseases, treated and followed in our nephrology clinic, were interviewed during 2015 to 2017. A kidney-disease patient questionnaire was used to interview the children or their caregivers. The study revealed that the most common renal disease among the participants was urinary tract infection (UTI, 35.7\%), followed by congenital diseases (34.1\%), then chronic renal failure (CRF, 11.6\%). There were several contributing factors of renal disease among the studied children, such as malnutrition, poverty, high rate of consanguinity, delayed diagnosis, and geographical location.
\end{abstract}

Key Words: Children, Renal disease

\section{INTRODUCTION}

Renal diseases are one of the major causes of morbidity and mortality in children. ${ }^{[1]}$ They can affect children in different ways; varies from completely treatable conditions without long-lasting consequences to serious disorders such as chronic kidney disease (CKD) and end-stage kidney disease. ${ }^{[2]}$ The causes of renal diseases in children widely differ from those that are responsible for the adult's illness. In children, renal diseases include steroid-resistant nephrotic syndrome, chronic glomerulonephritis, thrombotic microangiopathies, Wilms tumor, infections, structural causes (e.g., renal hypoplasia), genetic, and obesity. ${ }^{[3]}$

Furthermore, their patterns diverge according to race, genetic predisposition, geographical area, socioeconomic status, and cultural beliefs. ${ }^{[4]}$ For example, in developed countries, the advanced technology and early diagnoses contributed to higher reporting and early detection of congenital renal disorders. ${ }^{[3,5]}$ While, in developing countries, urinary tract infection (UTI) remains one of the most common causes of renal disorders. The incidence of UTI may reach $25 \%$, with chances of recurrence in more than half of them. It usually presents with non-specific symptoms, sometimes leading to Jordan.

*Correspondence: Najah Sami Shawish; Email: shawishns@yahoo.com; Address: Al-Balqa’ Applied University, Jordanian Ministry of Health, 
delayed diagnosis. ${ }^{[6-9]}$ Of all children with UTI, around $6.1 \%$ suffer from renal scars and chronic renal disease. ${ }^{[10]}$

The early diagnosis and treatment of renal diseases are essential in the prevention of renal scar, renal failure, and end-stage kidney disease (ESRD). ${ }^{[6,11]}$ However, the diagnosis of renal diseases could be tricky due to the fact that they present subtly, with non-specific signs and symptoms unrelated to the urinary tract, such as anemia, growth failure, hypertension, and unexplained fever, in addition to the fact that most of the renal diseases are painless. ${ }^{[7,12]}$

Understanding the spectrum of renal diseases and identifying contributing factors will promote early diagnosis and facilitate treatment. ${ }^{[2,3]}$ In Jordan, local circumstances such as high consanguinity level, ${ }^{[13]}$ low income, large families, parents' level of education, and residential location play a crucial role in the spectrum and are contributing factors that lead to the development of numerous childhood renal diseases. ${ }^{[14]}$ Recently, there is an increase in the amount of existing data on renal diseases in children. However, more studies are required to allow for international comparisons in the future. ${ }^{[2,12]}$

\section{MeTHODS}

\subsection{Research design and subjects}

A quantitative descriptive cross-sectional design was utilized. A convenient sample of 129 children accompanied by their caregivers was interviewed during the years 20152017. These children were diagnosed with renal diseases and treated in our patients' nephrology clinic in the Hashemite Kingdom of Jordan at Prince Hamza Hospital. It is a referral, tertiary, and teaching hospital affiliated to the Ministry of Health and Hashemite University, located in the Jordanian capital Amman.

\subsection{Research instrument}

The Kidney Disease Patient Questionnaire was used for data collection. It covers the following: socio-demographic data, type of renal diseases, and comorbid diseases. The questionnaire was tested for reliability by using Cronbach' Alpha test; it was reliable, and the coefficient value was 0.85 . It was reviewed by experts in the related fields to determine applicability and content validity.

\subsection{Ethical considerations}

Formal permission from the hospital ethics committee was obtained before the study. A consent form was attained from the children's caregivers after explaining the aim of the study. The participation was voluntary, which allowed them to refuse to participate in the study or withdraw at any time. Confidentiality, anonymity, and privacy were assured Published by Sciedu Press by using code numbers.

\subsection{Data analysis}

The Statistical Package for Social Studies (SPSS) version 24.0 was used. Data were coded and summarized using means values, standard deviation, and percentage to characterize the sample.

\section{Results}

\subsection{Socio-Demographic Data}

A convenient sample of 129 Jordanian children with renal diseases and their caregivers (86.0\% were mothers) were interviewed. Children's age ranged from less than twelve months to 13 years old, with a majority between 6 and 10 years old $(41.1 \%)$. More than one-half of the studied children were males $(58.1 \%)$. Regarding the parents' education levels, the results revealed that the majority of the parents had a secondary education level or lower $(77.5 \%$ of mothers, $76 \%$ of fathers). Most of these families are considerably large, and $42.6 \%$ have more than four children, with $77.6 \%$ having a markedly low monthly income of under 400 Jordanian dinars (JOD). The poverty line for Jordan is a monthly income of less than 500 JOD. ${ }^{[14]}$ Furthermore, $53.5 \%$ of the families resided in rural areas.

\subsection{Spectrum of renal disease}

UTI and congenital renal abnormalities were frequent in the present research, appearing in $35.7 \%$ and $34.1 \%$ of the interviewees, respectively. Congenital nephrotic syndrome was the most frequent congenital anomaly; it was seen in $26.3 \%$ of the population, while neurogenic bladder was seen in $7.8 \%$ of the participants. Chronic renal failure (CRF) was seen in $11.6 \%$ of the sample. Renal stones and other diseases represented less than $10 \%$ of all diagnostic categories (see Table 1).

Table 1. Distribution of the studied cases according to renal diagnosis $(n=129)$

\begin{tabular}{lll}
\hline Disease & No. & \% \\
\hline UTI & 46 & 35.7 \\
Congenital nephrotic syndrome & 34 & 26.3 \\
Chronic renal failure & 15 & 11.6 \\
Genetic disorder & 10 & 7.8 \\
Neurogenic bladder & 10 & 7.8 \\
Renal stone & 9 & 6.9 \\
Miscellaneous & 5 & 3.9 \\
\hline
\end{tabular}

The majority of the children $(67.4 \%)$ affected by these conditions were diagnosed within the first three years of age. Although a combination of different diagnostic methods 
was utilized $(31 \%)$, urine analysis was the highest-standard method used (28.7\%) (see Table 2).

Table 2. Distribution of the studied cases according to diagnosis time and methods $(n=129)$

\begin{tabular}{lll}
\hline Age of diagnosis & No. & $\%$ \\
\hline - $<1$ years & 32 & 24.8 \\
- 1-3 years & 55 & 42.6 \\
- 3-6 years & 30 & 23.3 \\
- 6-10 years & 11 & 8.5 \\
- 10-13 years & 1 & 0.8 \\
\hline Methods of diagnosis & No. & $\%$ \\
\hline - Urine analysis & 37 & 28.7 \\
- Radiology (X-rays, renal ultrasound, biopsy ) & 32 & 24.8 \\
- Blood test (KFT) & 20 & 15.5 \\
- 2+3 & 13 & 10.1 \\
- 1+3 & 8 & 6.2 \\
- 1+2+3 & 19 & 14.7 \\
\hline
\end{tabular}

\subsection{Other comorbid medical conditions}

More than half of the patients $(57.5 \%)$ have other medical conditions. The most frequently associated illness was hypertension $(24 \%)$, with diabetes mellitus appearing in a few cases $(3.1 \%)$ (see Table 3 ).

Table 3. Distribution of the studied cases according to other comorbid diseases $(n=129)$

\begin{tabular}{lll}
\hline Does the child have other diseases? & No. & \% \\
\hline Yes & 74 & 57.5 \\
No & 55 & 42.5 \\
Hypertension & 31 & 24.0 \\
Anemia & 25 & 19.4 \\
Bone diseases & 14 & 10.9 \\
Diabetes mellitus & 4 & 3.1 \\
\hline
\end{tabular}

\section{Discussion}

UTI was the most frequent renal disease among the participants. This could be linked to malnutrition due to poverty. The majority of children come from low socioeconomic classes $^{[14]}$ and large families. Low-income families are incapable of providing basic needs such as food, housing, and health care. ${ }^{[7,11,15]}$ Inadequate diet is directly associated with malnutrition. There is a close relation between malnutrition and infection as malnutrition affects the immune system and decreases resistance to infection. Conversely, an infection can worsen nutritional status. Worldwide, researchers have provided evidence suggesting that children suffering from malnutrition have a greater risk of UTI, with prevalence rates ranging from as low as $6 \%$ to as high as $37 \% .^{[7,11,16-18]}$

Furthermore, in addition to malnutrition, it is well recognized that childhood UTIs are frequently associated with underlying congenital abnormalities of the renal tract. Several studies have reported congenital renal anomalies as the most common renal diagnosis. ${ }^{[2,5,6,19,20]}$ In this research, the congenital renal abnormalities were the second most frequent renal disease. Congenital, hereditary, and genetic renal disease can be attributed to the high prevalence of parental consanguinity in the Jordanian community although there is a declining trend in consanguinity: "The level of consanguinity decreased from $57 \%$ in 1990 to $35 \%$ in 2012, according to the Jordan Population and Family Health Surveys." The rate is still considerably high. ${ }^{[13]}$ Several regionally oriented research studies have reported a high consanguinity rate as a significant contributor to congenital, hereditary, and genetic renal diseases, ${ }^{[11,16,18]}$ as opposed to researches in Western countries. ${ }^{[2,3,12]}$ The third most common renal disease reported in the current research was a CRF. In comparison to this research finding, CRF was higher in some countries such as Pakistan, Iran, and Turkey ${ }^{[1,16,23]}$ and less in Dubai. ${ }^{[24]}$ In this research, both UTI and congenital renal diseases are high, which may eventually lead to CRF. The results of another Jordanian study confirmed congenital anomalies as the major cause of CRF. ${ }^{[25]}$

In developed countries, congenital anomalies are responsible for about two-thirds of all cases of CRF, while in developing countries, renal infections were reported as the major cause of CRF ${ }^{[5,6,19]}$ Moreover, this research was able to identify significant contributing factors to renal diseases among the participants. Poverty is an important factor associated with malnutrition that increases the incidence of infection with UTI. The other factor is high consanguinity rate that lead to critical congenital renal abnormalities.

Another essential factor was residency. This study revealed that more than half of the participants live in rural regions (the majority of the Jordanian population lives in the capital and the surrounding areas $(60.9 \%){ }^{[14]}$ This could be explained by delayed diagnoses due to a shortage of pediatric nephrology health care, in addition to the long distance from the capital to have access to nephrology services. Families have to travel to the capital to treat their children in nephrology clinics. Children in rural areas are usually seen by primary care physicians or general Pediatricians. These physicians may be unfamiliar with the modes of presentation of some pediatric renal diseases, besides the lack of awareness among them regarding the importance of early 
diagnosis. Additionally, rural areas and secondary hospitals have fewer diagnostic facilities and treatment options. These factors often lead to inaccurate diagnosis, suboptimal treatment, and delayed referral to pediatric nephrology clinics. Similar results confirmed the effect of place of residence (rural areas) by other researchers. ${ }^{[17,23]}$

Another factor that might cause a delay in seeking health care is the educational levels of the caregivers. In the present study, the majority of the caregivers were mothers. Their education was less than the secondary level. Lower maternal education may affect the perception of the importance of looking for and starting early treatment; similar findings were reported by other researchers. ${ }^{[17,18,26]}$

Additionally, more than half of the children in this research have a comorbid medical condition (hypertension, anemia, bone diseases, and diabetes mellitus). These conditions are associated with poor renal function. In spite of this association, the majority of research studies reported these diseases as risk factors for renal problems in adults rather than children. ${ }^{[2,4,21]}$ This opposes the findings reported by Wong et al. ${ }^{[27]}$

\section{REFERENCES}

[1] Murray CJ, Lopez AD. Measuring the global burden of disease. New England Journal of Medicine. 2013; 369(5): 448-57. PMid: 23902484. https://doi.org/10.1056/NEJMra1201534

[2] Domingo MM, Arizpe RM. Kidney disease in children. A public health problem. BOL Med Hosp Infant Mex. 2011; 68(4): 239-41.

[3] Kolvek G. Etiology and prognosis of chronic kidney disease in children: Roma ethnicity and other risk factors. University of Groningen. 2014; 75-77. Assessed on 23 Aug 2018.

[4] Kaspar CD, Bholah R, Bunchman TE. A review of pediatric chronic kidney disease. Blood Purification. 2016; 41(1-3): 211-7. PMid: 26766175. https://doi.org/10.1159/000441737

[5] Harambat J, Van Stralen KJ, Kim JJ, et al. Epidemiology of chronic kidney disease in children. Pediatric Nephrology. 2012; 27(3): 36373. PMid: 21713524 . https://doi.org/10.1007/s00467-011 $-1939-1$

[6] Sajid NK, Ahmad S, Sarwar I. Chronic renal failure in children. The Professional Medical Journal. 2014; 21(02): 280-9.

[7] Sharma IK, Garg KK, Saxena D, et al. Study to determine the prevalence of urinary tract infection and to identify the causative organism and their antibiotic sensitivity pattern in severe acute malnourished children. International Archives of Integrated Medicine. 2017; 4: 89-104.

[8] Shaikh N, Morone NE, Bost JE, et al. Prevalence of urinary tract infection in childhood: a meta-analysis. The Pediatric Infectious Disease Journal. 2008; 27(4): 302-8. PMid: 18316994. https: //doi.org/10.1097/INF.0b013e31815e4122

[9] Lee SJ. Clinical guideline for childhood urinary tract infection (second revision). Childhood Kidney Diseases. 2015; 19(2): 56-64. https://doi.org/10.3339/chikd.2015.19.2.56

\section{CONCLUSIONS AND RECOMMENDATIONS}

This study highlights the spectrum and contributing factors of renal diseases in children managed at Prince Hamza Hospital during the research period. UTI, congenital renal abnormalities, and CRF were the most common renal disorders. Geographical area, parents' level of education, poverty and malnutrition, delayed diagnosis, inadequate therapy, and social and cultural beliefs such as high consanguinity rates were the main contributing factors to renal diseases. The researchers recommend the following: more involvement of pediatricians and pediatric nephrologists in prevention, early diagnosis, and management to avoid the CKD; a national guideline for diagnosis and referral to pediatric nephrologists; and national renal health education programs.

\section{ACKNOWLEDGeMENTS}

The researchers would like to thank all of the children and their families.

\section{CONFLicts OF INTEREST Disclosure}

The authors declare they have no conflicts of interest.
[10] Park YS. Renal scar formation after urinary tract infection in children. Korean Journal of Pediatrics. 2012; 55(10): 367-370. PMid: 23133482. https://doi.org/10.3345/kjp. 2012.55.10.367

[11] World Health Organization. Urinary tract infections in infants and children in developing countries in the context of IMCI. Geneva: World Health Organization; 2005.

[12] White B. Diagnosis and treatment of urinary tract infections in children. American Family Physician. 2011; 83(4). Available from: www . aafp.org/afp

[13] Islam MM, Ababneh FM, Khan MH. Consanguineous marriage in Jordan: an update. Journal of biosocial science. 2018; 50(4): 573578. PMid: 28793942. https ://doi .org/10.1017/S002193201 7000372

[14] The Jordanian Ministry of Health (JMOH). Non-communicable disease directorate. National Registry of End-Stage Renal Disease (ESRD). Annual report 2016. Available from: www . moh.gov . jo

[15] Kamoun A. Spectrum of pediatric renal diseases in Tunisia. Saudi Journal of Kidney Diseases and Transplantation. 1997; 8(3): 317-319.

[16] Uwaezuoke SN. The prevalence of urinary tract infection in children with severe acute malnutrition: a narrative review. Pediatric Health, Medicine and Therapeutics. 2016; 7: 121. PMid: 29388594 https://doi.org/10.2147/PHMT.S107421

[17] Hidalgo G, Ng DK, Moxey-Mims M, et al. Association of income level with kidney disease severity and progression among children and adolescents with CKD: a report from the Chronic Kidney Disease in Children (CKiD) Study. American Journal of Kidney Diseases. 2013; 62(6): 1087-94. PMid: 23932090. https : //doi.org/10.1053/j.ajkd.2013.06.013

[18] Kilis-Pstrusinska K, Medynska A, Adamczyk P, et al. Diseaserelated social situation in family of children with chronic kidney 
disease-parentsassessment. A multicentre study. Annals of Agricultural and Environmental Medicine. 2014; 21(4). PMid: 25528938. https://doi.org/10.5604/12321966.1129951

[19] Kari JA. Pediatric renal diseases in the Kingdom of Saudi Arabia. World Journal of Pediatrics. 2012; 8(3): 217-21. PMid: 22886193. https ://doi.org/10.1007/s12519-012-0360-6

[20] Gupta T, Goyal SK, Aggarwal A. Congenital renal anomalies in the Indian population. Journal of Postgraduate Medicine, Education, and Research. 2017; 51:12-16. PMid: 28924342. https: //doi.org/10.5005/jp-journals-10028-1226

[21] Derakhshan A, Al Hashemi GH, Fallahzadeh MH. Spectrum of inpatient renal diseases in children "a report from southern part Islamic Republic of Iran". Saudi Journal of Kidney Diseases and Transplantation. 2004; 15(1): 12-17.

[22] Moorani KN, Asim S, Shahid A. Pattern of Kidney Diseases in Children. Pakistan Pediatric Journal. 2013; 37(1): 26-33.
[23] Soylemezoglu O, Duzova A, Yalçınkaya F, et al. Chronic renal disease in children aged 5-18 years: a population-based survey in Turkey, the CREDIT-C study. Nephrology Dialysis Transplantation. 2012; 27(suppl_3): iii146-151. PMid: 23115139. https : //doi.org/10.1093/ndt/gfs366

[24] Abou-Chaaban M, Al Murbatty B, Majid MA. Spectrum of pediatric renal diseases in Dubai. Saudi Journal of Kidney Diseases and Transplantation. 1997; 8(3): 310-313.

[25] Hamed RM. The spectrum of chronic renal failure among Jordanian children. Journal of nephrology. 2002; 15(2): 130-135.

[26] Abu-Ouf NM, Abualhamyl AS, AlJahdali NF, et al. Parental perceptions of their child's kidney disease. Current Pediatric Research 2016; 20(2): 219-226.

[27] Wong CJ, Moxey-Mims M, Jerry-Fluker J, et al. CKiD (CKD in children) prospective cohort study: a review of current findings. American Journal of Kidney Diseases. 2012; 60(6): 1002-1011. PMid: 23022429. https://doi.org/10.1053/j.ajkd.2012.07.018 